\title{
Economia social: conceitos, fundamentos e tipologia
}

\author{
Joaquim Manuel Croca Caeiro \\ Instituto Superior de Serviço Social de Lisboa (ISSSL), \\ Universidade Lusíada de Lisboa
}

Este artigo mantém a ortografia vigente em Portugal

\section{Economia social: conceitos, fundamentos e tipologia}

Resumo: O presente artigo analisa as questões relativas ao conceito de economia social, na sua abordagem histórica e dinâmica actual, procurando ultrapassar as confusões terminológicas que se colocam àquele conceito. É ainda intenção do autor, definir as principais características e fundamentos da economia social, actores e respectiva tipologia. O seu objectivo fundamental é o de investigar a realidade económico-social, nomeadamente a portuguesa, num contexto de intervenção da sociedade civil na procura de soluções para os problemas sociais que se vão colocando com maior acuidade. Efectivamente, impõe-se reflectir sobre esta dinâmica, num tempo em que não se deixa de assumir a continuidade da crise do Estado-providência e dos Estados, sobretudo os mais tipicamente integrados neste modelo, que mostram uma dificuldade crescente na manutenção daquele modelo e sobretudo no seu financiamento.

Palavras-chave: Estado, mercado, economia social.

\section{Social Economy: Concepts, Reasons and Typology}

Abstract: This article analyzes the concept of social economy, considering it historically as well as its current dynamic. It strives to go beyond terminological confusion about the concept. The principal characteristics and foundations of social economy, its actors and the respective typology are also defined. The fundamental objective of the paper is to investigate the economic-social reality, particularly that of Portugal, in a context of intervention of civil society in the search for solutions to the sharpest social problems. The paper reflects on this dynamic, considering the continuity of the crises of the welfare State and of Governments, above all those most typically integrated to this model. It found a growing difficulty in the maintenance of that model and above all in its financing.

Key words: State, market, social economy. 


\section{Delimitação do conceito de economia social}

O conceito de economia social tem nos últimos tempos sido alvo de um intenso e animado debate, no sentido da procura de um fio condutor suficientemente forte para permitir de forma consistente entender o que se pretende significar. Tem sido também objecto de alguma dificuldade a tentativa de distinção entre economia social e os outros conceitos relacionados de uma ou outra forma com as actividades ligadas à intervenção social, especialmente o de 'terceiro sector', 'organizações sem fim lucrativo' ou 'economia solidária', sendo a escolha a mais das vezes fundamentada em critérios subjectivos ou pelo menos pouco concretos do ponto de vista científico ${ }^{1}$.

Pode, todavia, entender-se com alguma facilidade, que os conceitos de economia social, de terceiro sector e economia solidária, sejam utilizados de forma indistinta e até confusa por muitos autores que analisam esta realidade. Não se afigura fácil tal distinção e muitas vezes é mais fácil não a fazer, optando-se pelo uso indiscriminado do termo. Aliás, parece-nos que em muitas circunstâncias a tentativa de separação que se pretende fazer não vai além de puro e pretenso preciosismo linguístico. O que prevalece para lá das questões de caracterização conceptual é a realidade social e económica em que se insere a economia social ou o terceiro sector, fundamentando-se num evidente distanciamento quer do mercado quer do Estado ainda que sem renegar a qualquer destas realidades.

Colocada a questão conceptual e dentro dos condicionalismos que se apresentam, não podemos deixar de referir que a utilização daqueles termos sofre de ambiguidades várias, sendo mais evidente a clivagem virtual entre as duas realidades.

Pretendemos, por isso centrar desde já a nossa atenção nas questões terminológicas, mas impõe-se antes de análise mais precisa do conceito de economia social, se evidencie a sua evolução e a sua actualidade. $\mathrm{O}$ conceito de economia social deriva da terminologia francesa, e remonta às práticas de solidariedade interclassiatas enquanto reacção às transformações económicas e sociais da revolução industrial influenciada pelo pensamento dos socialistas utópicos do século $19^{2}$, dando origem a formas de organização como as associações, as cooperativas e as mutualidades. No essencial, ela começou a ser utilizada pelos autores contestatários ao modelo dominante, acusado de separar as regras de funcionamento da economia das regras morais.

\section{2 Breve evolução histórica}

O conceito de economia social surge cerca de 1830, quando Charles Dunoyer publica em Paris um tratado de economia social, surgindo na mesma dé- cada na Universidade de Lovaina um curso com a designação de economia social. Nesta linha, surge um conjunto de escolas teóricas de que se salientam, a socialista, cujos percursores são os socialistas utópicos e tendo o contributo de Marcel Mauss (1872-1950), defensor de uma economia de socialização voluntária e de Benoit Malon (1841-1893), cujo tratado de economia social (1883) tinha na sua base idêntica perspectiva; a escola social-cristã reformista, que, pela mão de Fréderic Le Play (18061882), inaugurou uma sociedade de economia social e uma revista com o mesmo nome. Le Play, aprova o desenvolvimento das cooperativas com um objectivo reformista não sendo, no entanto, favorável a uma transformação radical da sociedade; a escola liberal, dirigida em primeiro lugar por Charles Dunoyer (1786-1862) e mais tarde por Frédéric Passy (1822-1912) coloca a sua perspectiva teórica na liberdade da economia e no afastamento da intervenção do Estado com recurso ao princípio da auto-ajuda. Associam-se ainda a esta escola Leon Walras (1834-1910), pela importância que atribui às associações populares, e John Stuart Mill (18061873) que na Inglaterra defende a superação do proletariado através das associações de trabalhadores; a escola solidária, ligada a Auguste Ott (18141892) que publica um tratado de economia social e sobretudo a Charles Gide (1847-1932) ${ }^{3}$. É ele quem marca um período áureo da economia social francesa, e concretiza o espírito do solidarismo pelo qual será possível a abolição do capitalismo e do proletariado sem sacrificar a propriedade privada nem as liberdades provindas da revolução. A ajuda mútua e a educação económica através da cooperação podem por si só promover a transformação do homem.

O mérito principal destas escolas é o de demonstrar o pluralismo político e cultural que caracteriza os primórdios do desenvolvimento da economia social e que até hoje se mantém.

Podemos no que concerne à evolução da economia social, pelo menos do ponto de vista académico, distinguir cinco períodos, como seguem.

a) A génese da economia social (1791-1848)

Este período é marcado pela Revolução Francesa e bafejado pelos ideais da liberdade, da fraternidade e da igualdade, tendo como resultado o início do movimente associativo ligado ao proletariado e às organizações obreiras. As cooperativas começam também a dar os seus primeiros passos, no sentido de potenciar o emprego e reduzir as desigualdades sociais características do período em questão. O fim deste período é marcado pela tomada de Paris (Comuna de Paris) e pela tentativa de criar um governo autogestionário, assente no poder proletário e as ideias de alguns idealistas como Louis Blanc, vão no sentido da promoção das associações proletárias e das cooperativas. 


\section{b) A questão social e o movimento operário} (1850-1900)

Com o fim da Comuna de Paris, a repressão não esperou para se fazer sentir e o Estado volta de novo a assumir o seu papel secular.

Pela primeira vez na história do papado, o papa Leão XIII vê-se forçado a intervir na esfera temporal, através da encíclica Rerum Novarum. O papa proporia o regresso aos tempos de antes da revolução e de novo ao associativismo das profissões, no que se designava de corporações.

Do ponto de vista das instituições de economia social, vão-se desenvolvendo os movimentos associativos operários (determinados pelas correntes que na época se afirmavam contrárias ao status quo dominante: marxismo, anarquismo e socialismo revolucionário).

c) Os regimes totalitários e a contestação ao liberalismo (1901-1945)

Os primeiros anos do século 20 seriam marcados por dois momentos fundamentais e violentos: a Primeira Guerra Mundial e a Revolução Russa de 1917. Neste contexto, os movimentos totalitários, cuja base ideológica vai ser a contestação ao liberalismo e o papel determinante do Estado na condução da sociedade, assumem uma posição importante. O fascismo italiano, o nazismo alemão, o Estado Novo português e o tenentismo brasileiro, são algumas dos resultados adquiridos no decurso dos primeiros trinta anos daquele século.

Até a Segunda Guerra Mundial, assiste-se a uma fragmentação do núcleo cooperativista e mutualista nascido do movimento associativo, através da estruturação das cooperativas em ramos sectoriais pelas dificuldades de continuidade do movimento operário e as dificuldades geradas pelas duas guerras mundiais. Tudo isto, unido à divisão do movimento associativo em várias direcções, conduziria a um distanciamento e falta de coesão das actividades cooperativas, mutualistas e associativas (DEFOURNY, 1992).

A Grande Depressão, iniciada em 1929 e o New Deal nos Estados Unidos, seriam elementos determinantes na mudança das mentalidades e nas preocupações sociais. J. M. Keynes, e a sua Teoria do juro, do emprego e da moeda, e Lord Beveridge, criariam o espaço teórico para os anos do Estadoprovidência que marcariam o período seguinte e um contexto maior de intervenção do Estado.

d) O Estado-providência e os direitos sociais (1945-1975)

A seguir ao final da Segunda Guerra Mundial e ao mesmo tempo que se vai implementando e desenvolvendo o Estado-providência com base no modelo keynesiano de intervenção do Estado na economia, o conceito de economia social vai ser relegado para segunda instância em termos de importância e de uma vez que o Estado passa, por si só, a intervir no mercado e a corrigir as suas 'falhas' sem necessidade a outras entidades económicas. No mesmo sentido, terminologicamente, a expressão 'economia social' vai-se empregando em sentidos cada vez mais amplos e diversos do original, passando também a designar os campos de análise sócio-económica, ou seja, para designar a vida em sociedade, do indivíduo e dos grupos sociais, impondo por via disso a grande dispersão do conceito.

É todavia, a partir dos anos 1970, como resultado da crise do Estado-providência que a problemática da economia social se volta a colocar, com acuidade, e mais uma vez, de forma preponderante em França, tendo por base a proximidade entre os movimentos cooperativos e mutualistas franceses, a percepção da existência de interesses mútuos e adesão ao grupo do movimento associativo.

e) A crise do Estado-providência e o redimensionamento da economia social (1975-2006)

Da contribuição dos movimentos referidos e pelo desenvolvimento e crescimento dos movimentos cooperativo, associativo e mutualista, a economia social volta de novo a adquirir dimensão e importância. Assiste-se ao desenvolvimento de apoios financeiros à economia social e às suas organizações, a um aumento do emprego e ao desenvolvimento de associações locais e de cooperativas dos mais variados tipos. Ligado a esse movimento, surge também a tentativa de promoção da inclusão social, quer pelo emprego quer pela constituição de associações de âmbito social.

Em 1975, nasce o Comité Nacional de Coordenação das Actividades Mutualistas, Cooperativistas e Associativistas (Cnlamca) que lança em 1978, em Bruxelas, um debate europeu sobre economia social. Em 1981, com o reconhecimento do seu poder político, pela criação de uma Delegação Interministerial para a Economia Social (DIES) pelo governo francês, ela passa a depender de uma Secretaria de Estado.

Fora da perspectiva francófona, a história da economia social, não tem um enquadramento tão vasto e diversificado, ainda que não deixe de, em alguns países, já ocupar um lugar de destaque no contexto económico e social.

Em Portugal, a tradição assenta essencialmente nas misericórdias que desde o século 18 assumiram uma componente de intervenção junto das populações mais desfavorecidas e nas mutualidades que no decurso do século 19 e alguns anos do século 20 tiveram grande intervenção na área socio-económica

\subsection{A confusão terminológica: economia social, economia solidária, terceiro sector, non profits organizations}

Já fizemos reparo ao paradoxo terminológico e conceptual da expressão 'economia social', princi- 
palmente face à qualificação 'social' na economia, pois, aquela está por natureza ligada à actividade económica e esta é eminentemente na sociedade uma actividade social. Não podemos também deixar de fazer reparo à própria ambiguidade do conceito e até à sua imprecisão, dada a inexistência de um consenso generalizado para a sua caracterização ${ }^{4}$.

Por outro lado, tais dificuldades resultam em grande parte da dicotomia existente entre economia pública e economia privada e dos campos de actuação de cada uma delas. Se estas duas economias têm um espaço de intervenção preciso, delimitado e muito concreto, já a economia social, acaba muitas vezes por ser atirada para um espaço de intervenção intermédia entre aquelas o que dificulta ainda mais a sua caracterização e delimitação.

A economia como 'social' situa-se

[...] numa perspectiva metodológica diferente da economia ortodoxa face à definição do problema económico, em que desaparece a dicotomia homem económico-homem social e em conjunto com os problemas de afectação de recursos se analisam também os relativos à distribuição, condições de produção, desemprego, pobreza e qualidade de vida (MONZÓN, 1992, p. 12).

Donde resulta que a perspectiva metodológica da economia social facilita a ligação dos problemas económicos com o seu ambiente natural contribuindo para o estabelecimento de conexões teóricas entre os sistemas económicos e ecológicos.

Por outro lado, muitas outras definições se apresentam no que à economia social respeita, como podemos verificar pelos excertos seguintes ${ }^{5}$ :

Numa palavra, a economia social [...] situa-se na área da liberdade e da função social do ter e do ser ao serviço da comunidade humana e do desenvolvimento harmonioso da sociedade numa perspectiva de promoção, simultaneamente, individual e colectiva.

Nós vemos a economia social como o conjunto das actividades com dimensão económica e não de natureza económica, realizadas por entidades privadas sem fins lucrativos, com objectivos sociais [...]. Devemos considerar economia social as diferentes entidades privadas sem fins lucrativos, cujo produto é a solução dos problemas sociais. Podemos depois ser exigentes e considerar apenas as que desenvolvem actividades mais próximas do mercado [...]. Em qualquer dos casos uma instituição deveria ter condições para existir sem o financiamento governamental.
O valor intrínseco do produto é uma coisa importante para mim, o produto não é um mero instrumento para a obtenção de lucros, é algo válido por si próprio e válido numa perspectiva social [...]. O problema que se põe é o que fazer com esse diferencial positivo e aí eu admito que possa haver uma distribuição porque penso que a economia social não tem de ser à priori contrária à ideia de lucro. A economia social só verdadeiramente existe quando uma empresa desenhada segundo um modelo concorre no mercado como uma forma alternativa, uma maneira alternativa de estar no mercado.

Face ao que se vem dizendo e de um ponto de vista operacional, podemos definir a economia social como o

[...] grupo de empresas e instituições que para além da sua diversificação jurídica e heterogeneidade de funções, está ligado através de uma ética comum assente na solidariedade e na prestação de serviços aos seus membros e no interesse geral, sendo as cooperativas a sua representação mais genuína (BAREA; MONZÓN,1992, p. 32).

Considera-se assim que a economia social tem características próprias para responder a um enquadramento económico e social específico, ao qual nem a economia pública nem a privada conseguem ou desejam dar respostas. Resulta assim que a economia social se define por um intervalo entre o Estado e o mercado, quer no sentido da concretização das acções que o Estado não pretende resolver, quer no daquelas que a economia privada não vislumbra interesses lucrativos para a sua realização.

$\mathrm{O}$ outro dos conceitos em análise é o de terceiro sector. Este tem em Portugal uma crescente utilização pela qual costuma referir-se o conjunto das organizações de interesse mútuo em conjunto com aquelas que, embora dependentes de subsídios do Estado e do mecenato das empresas privadas, centram-se no campo da acção e da coesão social. Deste ponto de vista, as instituições do terceiro sector têm um carácter privado, sem fins lucrativos, apresentam uma gestão autónoma, mas actuam na esfera pública como forma de satisfação de necessidades globais.

Este conceito tem origem na escola anglosaxónica, onde a tradição vai no sentido de considerar como elementos determinantes na esfera económica da intervenção social as instituições sem fins lucrativos, as quais se apresentam com uma vocação interclassista nas formas de solidariedade praticadas. As organizações sem fins lucrativos podem definir-se como o conjunto de entidades que são: organizadas, privadas, não distribuidoras de lucro, autogovernadas e voluntárias. São entidades organizadas, por apresentarem uma coerência institucional, nome- 
adamente pela realização de reuniões com regularidade, a existência de procedimentos de funcionamento e algum grau de permanência organizacional. São privadas, por se encontrarem afastadas do Estado. Tal não significa, contudo, que não possam obter financiamentos governamentais. São entidades não distribuidoras de lucro, no sentido em que nenhum dos seus membros pode receber qualquer lucro gerado pela sua actividade. Isto significa que, gerandose o lucro, ele tem de ser investido em melhoramentos da própria organização. São auto-governadas, ou seja, criam internamente o seu próprio sistema de gestão, sem necessidade de controlo por parte de quaisquer entidades externas. São entidades voluntárias, porquanto, uma parte significativa do seu rendimento é proveniente de contribuições voluntárias.

$\mathrm{O}$ conceito de terceiro sector apresenta, face ao que se viu, um cariz mais abrangente do que o de economia social situando-se numa perspectiva alargada de análise da economia e das suas implicações do ponto de vista social.

Outro conceito que voltou a adquirir grande importância e visibilidade, nomeadamente em França e noutros países nos sectores ligados à doutrina social da igreja, foi o de economia solidária. Para esta nova realidade identificada como uma 'economia alternativa' assume importância primordial a intervenção ecológica, o desenvolvimento local e a autogestão como forma de organização interna. É também em França que radica a sua génese e inicia-se com a criação da Agência de Ligação para o Desenvolvimento de uma Economia Alternativa (ALDÉA). Ainda que ligada também ao sector cooperativo e associativo, não deixa de promover o financiamento de microprojectos artesanais. Como outras características essenciais, a solidariedade e a autonomia ganham foros privilegiados.

A economia solidária apresenta-se como um tipo de economia alternativa, principalmente ao que entende ser o conformismo e a objectivação da economia social. Com efeito, em 1993, em França, a revista Travail, apresenta um dossier designado simplesmente por 'economia solidária', que conta com a colaboração dos principais teóricos deste tipo de economia: Alain Archimbaud, Alain Caillé, Bernard Ème, Bernard Enjolras, Jean-Louis Laville, Patrice Savage, entre outros.

O que distingue então a economia solidária da economia social? É no essencial, a consideração de que
[...] a iniciativa provém dos cidadãos que estão resolvidos a fazer alguma coisa, porque não estavam completamente excluídos ou desesperados e porque integram no seu comportamento individual a utilidade de todos, ainda que por si próprio, de libertar as ligações sociais, acumular o capital, melhorar o seu meio ambiente, de defender os vizinhos (LIPIETZ, 2001, p. 51)

De outro modo, alguns autores entendem a economia solidária como a consciência externa da economia social, definida no sentido de actividade económica, sendo a sua lógica o sistema de valores dos actores com base nos critérios de gestão das suas instituições.

Finalmente e face ao que fica dito, podemos, no que respeita ao conceito de economia social, considerá-lo segundo duas vertentes: a primeira, a francófona, define como o conjunto de instituições sem fim lucrativo com personalidade jurídica própria que produz serviços fora do mercado, a favor das famílias e cujos excedentes, se os tiverem, não podem ser apropriados pelos mesmos agentes económicos que as controlam ou financiam.

Na segunda, a vertente anglo-saxónica, o seu conceito obedece a cinco critérios fundamentais tendo por base a classificação da Jonh Hopkins University e devem:

a) respeitar o principio da não distribuição de benefícios entre os seus proprietários ou administradores, mas, se eventualmente estes existirem, só devem destinar-se em exclusivo ao desenvolvimento dos seus fins ou a novos investimentos;

b) ser entidades privadas;

c) ser entidades formalmente organizadas, com estrutura e objectivos definidos;

d) ser auto-geridas e com autonomia face ao sector público e ao sector empresarial privado;

e) ter capacidade de mobilização de recursos voluntários.

\subsection{Características e fundamentos da economia social}

São critérios jurídicos, económicos e sociológicos que de forma combinada possibilitam delimitar e estruturar o campo de intervenção das organizações de economia social. Neste aspecto, as cláusulas gerais dos estatutos jurídicos das instituições resultam 
a regras passíveis de reagrupar em torno de quatro grandes princípios, que são a:

a) identificação recíproca das pessoas associadas e da actividade empresarial;

b) igualdade dos associados, independentemente da sua participação no financiamento e na actividade destas empresas e

c) possibilidade de divisão dos excedentes entre os associados de forma proporcional à sua participação na actividade económica;

d) propriedade colectiva dos benefícios investidos de forma permanente.

Da análise do conceito de economia social, resultam quatro princípios determinantes:

a) finalidade de prestação de serviços aos membros da colectividade;

b) autonomia da gestão;

c) processo de decisão democrática e

d) primado do trabalho e das pessoas sobre o capital e a repartição do rendimento.

Pode então, afirmar-se que a economia social recobre duas realidades que se interligam, a saber "uma forma alternativa de estar na economia (nem pública, nem privada capitalista) e o trabalho social ou assistencial sobre as camadas da população em processo de exclusão" (NUNES; RETO; CARNEIRO et al, 2001, p. 6). A sua designação advém do seu fim ser o bem-estar social, o desenvolvimento local e a solidariedade, situando-se, por conseguinte, na área da liberdade e da função social do ter e do ser ao serviço da comunidade humana e do desenvolvimento harmonioso da sociedade numa perspectiva de promoção, simultaneamente, individual e colectiva.

Face ao que fica dito, devemos entender a economia social, com base num conjunto de valores que evidencia uma finalidade social da sua actividade e racionalidade própria dos agentes, ou seja, ausência da finalidade do lucro na sua actuação, preocupação pela procura não solvente, pela satisfação de necessidades sociais onde surgem aquelas que não são satisfeitas pelo mercado.

Dentro deste contexto, importa ainda analisar as relações da economia social com o sector privado tradicional e com o sector público. Tais relações fazem sentir-se essencialmente ao nível da participação dos trabalhadores na propriedade, na gestão e nos resultados da empresa. É por esta via, que as empresas cooperativas se assumem em virtude das suas regras como "laboratórios de inovação social e repartição do poder" (DEFOURNY, 1991, p. 32), do mesmo modo que as associações que se enquadram neste tipo de economia se afirmam pela garantia de "uma série de actividades que dão resposta a procuras, que a maior parte das vezes não podem ser quantificadas monetariamente, ou que não oferecem uma rentabilidade suficiente para promover a atracção de empresas orientadas para o lucro" (PÉREZ, 1999, p. 175).
No que se refere à relação com o sector público, e se entrarmos em linha de conta com as três funções principais deste último sector (produção, redistribuição e regulação), a Economia Social tem uma acção complementar. Apresenta-se como uma espécie de entreposto entre o Estado e o mercado, servindo para que aquele possa incentivar a criação de estruturas empresariais capazes de integrar os objectivos de eficiência económica com os de bem-estar social.

É por isto que a economia social participa na função produção, através da prestação de serviços de utilidade colectiva, em todos os sectores, sociais, culturais, apresentando as instituições integrantes do sector à força da iniciativa privada e à rapidez de intervenção que faltam ao âmbito público.

Também na função redistribuição, a economia social exerce um papel importante. Efectivamente, as suas instituições podem ser (e são-no já) uma forma nova para a realização de uma melhor distribuição do rendimento, a qual pode ser feita através de uma forte vontade política do ponto de vista da alteração normativa que regula o sector e ainda através de ajudas para a superação dos pontos débeis o permitindo uma posição concorrencial no mercado (BAREA; MONZÓN, 1992).

No que respeita à função regulação, o papel da economia social mostra-se essencialmente nas políticas de emprego e na sua intervenção para a solução do problema do desemprego. Neste caso, as instituições de economia social podem, através dos agentes locais culturais e sociais, promover a reorganização de sectores mais depauperados, deixando ao Estado a possibilidade de se preocupar com as grandes questões de reestruturação económica. Para além disto, o Estado tem interesse em apoiar as instituições da economia social, uma vez que estas têm a capacidade para mobilizar recursos que não o poderiam ser de outra forma, encontrando em tais organizações uma garantia através das suas regras de funcionamento democrático.

\section{Os actores da economia social: as famílias, as empresas e as instituições}

No âmbito da actividade económica em geral, os agregados fundamentais são as famílias, as empresas e o Estado. No que se refere à economia social, o Estado passa a ter um papel menos significativo do ponto de vista da sua intervenção directa, ganhando dimensão, em sua substituição, as instituições de carácter social, e em países com tradição, os sindicatos.

No que respeita a esta última instituição, e no caso português, a sua tradição na intervenção ao nível da promoção do bem-estar social é quase inexistente, ao contrário do que acontece em países como a França e a Bélgica, por exemplo. 
Analisemos então cada uma destas instituições, sem nos preocuparmos com os sindicatos, em face do que atrás dissemos.

\subsection{As famílias}

As famílias são por definição e do ponto de vista económico, as unidades de consumo. E, é neste contexto que as vamos observar.

É do trabalho que a maioria das famílias adquire os seus recursos e o salário constitui o núcleo fundamental para a promoção do seu bem-estar, do qual grande parte se destina ao consumo. Efectivamente, o trabalho constitui o factor principal de rendimento, mas não só, também o lazer é imprescindível. Este reflecte a parte do dia em que o trabalhador não exerce actividade, contribuindo para garantir ou manter o seu bem-estar. E, é nesta dicotomia, trabalho-lazer que a família vai gerindo o seu bem-estar.

Por este motivo, a família vai de forma sistemática definindo a sua decisão de trabalhar ou não (nomeadamente, através de um ou outro dos seus membros) em função da vantagem comparativa que atribui ao trabalho face ao lazer. Isto significa que um dos membros do casal pode, em determinadas conjunturas, optar por reduzir ou deixar o mercado de trabalho. E quando é assim, é a mulher na maior parte das vezes que toma tal decisão.

A realidade dos vários países, e a qual Portugal também não foge, é a determinada pela globalização. E por sua influência, os mercados têm nos últimos anos tendência suplementar para a flexibilização do mercado de trabalho associada a uma desregulação crescente, pela sua informalização e acentuada fragmentação. No que se refere à flexibilização ela é caracterizada pela procura de mão-de-obra altamente qualificada e pela margem significativa de trabalhadores sem qualificação que se mantém no desemprego ou em situações precárias de emprego. Já quanto à informalização, ela advém do crescente aumento da economia paralela, da subcontratação, trabalho a tempo parcial involuntário. No que se relaciona com a fragmentação, ela é imposta pela crescente individualização das relações económicas e proliferação do trabalho atípico e muitas vezes precário.

O carácter acentuado destas realidades, a par com uma ausência ou reduzida intervenção do Estado na regulamentação do mercado de trabalho, condiciona o emprego e a estabilidade económico-financeira daqueles que menos qualificações ou menos capacidade têm para se impor no mercado de trabalho mais exigente e com melhores salários ${ }^{6}$.

É por via dessas observações que a economia social tem vindo a adquirir um espaço significativo nos contextos das famílias e ao mesmo tempo tem assumido funções que estavam tradicionalmente atribuídas ao Estado ou às empresas de forma geral. Garantindo, assim, condições para promover a inclusão social daqueles que não conseguem assumir um espaço na economia capitalista e concorrencial que caracteriza o mercado de trabalho contemporâneo.

E através da economia social que o espírito do empreendedorismo social se tem feito sentir e contribuído para a dinamização do mercado de trabalho, e bem assim como resposta à incapacidade do mercado e essencialmente do Estado para assegurar o pleno emprego, como o havia conseguido nos anos 1930 a seguir à Primeira Guerra Mundial

\subsection{As empresas}

As empresas constituem o núcleo essencial da produção de bens e serviços. E, em última instância, são elas que determinam o salário dos trabalhadores e, por assim dizer, das famílias. No que se refere ao salário e à sua fixação, e numa lógica economicista, depende da produtividade marginal do trabalho, pelo menos teoricamente. A produtividade marginal, enquanto traduz o suplemento de produção aquando do acréscimo do factor trabalho, implica que este se encontre fundamentalmente ligado à produção. Efectivamente, uma produtividade elevada implica um salário elevado, reflectindo este uma determinada hierarquia de produtividade e de salário. De outra parte, o posto de trabalho e o salário são dependentes de outras circunstâncias para além da produtividade: da componente educacional, individual ou colectiva e da experiência do trabalhador.

Tal como a família, também as empresas são organizações sociais. E neste domínio relevam as regras de funcionamento, principalmente no sentido da promoção da cooperação entre trabalhadores e empregadores. E tal cooperação é tanto mais necessária quanto à partida, pois nem o trabalhador conhece o empregador nem este conhece o empregado (não sabe se é pontual, se terá capacidade de integração no grupo de trabalho, etc.).

Temos referido a questão da empresa no seio da economia de mercado e portanto com relação ao facto deste se preocupar acima de tudo com a concorrência e a competitividade, sistema pelo que os mais debilitados na sociedade têm grandes dificuldades de integração. Muitas vezes, aqueles com problema individual ou social acabam por ser excluídos de uma economia onde a maximização do lucro domina o espírito do empresário. Logo, a componente social da economia acaba por ser a âncora para a promoção da inclusão social, do emprego e da garantia de satisfação de necessidades consideradas mínimas por parte dos indivíduos. É a economia social que, em face das características dominantes da sua organi- 
zação, promove a constituição de empresas onde o mais importante não é a maximização do lucro, a concorrência e a competitividade, mas apenas a possibilidade de garantir um posto de trabalho, um salário e a satisfação de necessidades básicas e sociais mínimas. É para além disso, a economia social, um ponto determinante para a aquisição de cidadania e participação por parte dos indivíduos, sobretudo daqueles que estão, de uma forma ou de outra, afastados da esfera social.

\subsection{As instituições}

Mais do que as empresas, são as instituições sociais quem têm um papel decisivo no âmbito da economia social. Para além de proporcionar modelos de gestão diferentes e da repartição do poder entre os seus membros, também elas têm um contributo diferente: não são públicas nem privadas. No seu conjunto, e como se verá de seguida, são as associações, e no caso português, em especial as IPSS, as mutualidades, algumas fundações e acima de tudo as misericórdias quem exerce a dinâmica fundamental no desenvolvimento da economia social. São as instituições quem detém o verdadeiro espírito da economia social e por via dele impulsionam a intervenção social na promoção do emprego, do bem-estar social, da saúde, do desenvolvimento regional e local e a inclusão dos mais desfavorecidos.

\section{Tipologia das empresas de economia social}

Para a avaliação da tipologia das empresas de economia social, procuramos seguir de perto os critérios comunitários tendo, no entanto, em linha de conta os que balizam o sector nos países onde ela tem uma implementação mais forte, como é o caso de França e Espanha.

De um modo geral, os critérios de classificação das empresas integradas na economia social são os seguintes:

a) são organizações autónomas em relação ao Estado, do ponto de vista da sua gestão;

b) a propriedade é institucional e não é objecto de repartição entre os participantes;

c) são organizações cujo objectivo, não é a maximização do lucro, prevendo em alguns casos restrições à distribuição dos excedentes (o mais usado é a ausência de relação entre o capital e a participação nos lucros);

d) têm gestão democrática e participativa;

e) há o predomínio do factor trabalho sobre o capital, dando ênfase à qualidade do serviço a prestar e ao desenvolvimento dos seus trabalhadores;

f) possuem modelo organizacional idêntico aos dos restantes sectores; g) as suas formas organizacionais são muito diversificadas e

h) seu objectivo fundamental é a prossecução do bem-estar ou do equilíbrio social.

Deste conjunto de critérios resultam as várias formas componentes de organizações integrantes da economia social que tradicionalmente se distinguem em termos gerais em cooperativas, mutualidades, associações e fundações. No entanto, importa ainda referir que em cada país as organizações de economia social assumem tipologias diferenciadas, pese, embora as mais das vezes, tal diferenciação seja mais evidente do ponto de vista da forma e menos no que respeita ao seu conteúdo. Assim em Portugal, podemos considerar no âmbito da economia social, as misericórdias, as mutualidades, as cooperativas, algumas fundações e as Instituições Particulares de Solidariedade Social (IPSS). Em Espanha, para além das três primeiras categorias e das fundações, surgiu recentemente uma nova tipologia, as sociedades anónimas laborales ${ }^{7}$. Em França, são dominantes as cooperativas, as mutualidades e algumas associações. Já na Itália, o predomínio vai para essas mesmas características, o mesmo acontecendo com a Bélgica, Áustria e Dinamarca.

Distinta é a caracterização dos EUA, onde a distinção se faz em termos da existência de um plano primário, onde se situam as cooperativas e organizações sem fins lucrativos, e de um plano secundário, integrado pelas mutualidades e organizações cuja propriedade é dos trabalhadores.

Analisemos entretanto cada um dos tipos de organizações apontadas acima e principalmente apontando as principais características face à tradição portuguesa.

\subsection{As cooperativas}

São o sector historicamente mais importante, continuando na actualidade a afirmar-se no contexto sócio-económico dos grupos sociais plurais, apresentando um forte cariz popular e com independência da actividade económica que pode desempenhar. Para além do mais, obedecem a um conjunto de regras que lhe atribuem uma inequívoca personalidade no seio dos movimentos sociais;

No quadro da Organização Internacional do Trabalho (OIT, 2007) as cooperativas são definidas como:

Associações de pessoas que se agrupam voluntariamente para satisfação de um interesse comum, para a constituição de uma empresa dirigida democraticamente, fornecendo uma parte equitativa do capital necessário e aceitando uma justa participação nos riscos e benefícios da empresa, e no funcionamento do qual os membros participam activamente. 

cional:

No que concerne ao enquadramento jurídico na-

As cooperativas são pessoas colectivas autónomas, de livre constituição, de capital e composição variáveis, que, através da cooperação e entreajuda dos seus membros, com obediência aos princípios cooperativos, visam, sem fins lucrativos, a satisfação das necessidades e aspirações económicas, sociais ou culturais daqueles (CÓDIGOCOOPERATIVO 1997, art. $2^{\circ}, 2007$ ).

Estas representam a parte que mais aproxima a economia social do sector privado clássico e a sua contribuição é por demais evidente ao nível do desenvolvimento económico e social, no que concerne ao aproveitamento dos recursos locais, à criação de emprego ou através da participação nos processos de produção mais intensivos em mão-deobra, por um conjunto de características que vão da agilidade à rapidez e capacidade de adaptação face a determinados desafios tecnológicos até à habilidade para suprir determinados problemas comerciais e técnicos que exigem um capital considerável.

As regras que as distinguem de outros tipos de sociedades baseiam-se em princípios que tiveram origem no próprio movimento cooperativo, designadamente nos Congressos de Paris (1937) e de Viena (1966) e consagrado no Código Cooperativo em 1997:

a) a liberdade de adesão sem discriminação em função do sexo, raça, idade, condição económica e social e convicções políticas e religiosas;

b) a democracia interna, com órgãos sociais eleitos por meios democráticos, atribuindo a todos os membros da cooperativa o direito de voto;

c) a participação económica dos membros que devem contribuir equitativamente para o capital das suas cooperativas e receberem uma remuneração limitada;

d) a autonomia e independência das cooperativas que deve ser assegurada mesmo no caso de acordos com outras entidades;

e) a educação, formação e informação;

f) o desenvolvimento da cooperação com outras entidades cooperativas à escala nacional e internacional e

g) o interesse pela comunidade

Quanto à sua classificação, as cooperativas podem ser de primeiro grau ou de grau superior, resultante do agrupamento entre diversas cooperativas. Por outro lado, a classificação das cooperativas é o resultado da contraposição entre a actividade da empresa e a posição dos seus membros, donde se distinguem as de consumo, as de produção, as de habitação e as de poupança e crédito.

\subsection{As mutualidades}

As associações mutualistas, enquanto instituições particulares de solidariedade social, assumem-se como uma das formas por excelência de economia social, principalmente se tiver em linha de conta o seu desenvolvimento histórico. Na actualidade nem sempre assim é, dada a existência de um conjunto de problemas ao nível da sua sustentabilidade enquanto sujeito de economia social, mormente por depender em muito da quotização dos seus associados.

Constituem seus fins fundamentais a concessão de benefícios de segurança social e de saúde e cumulativamente outros fins de protecção social e de promoção da qualidade de vida, pela organização e gestão de equipamentos e serviços de apoio social e actividades que visem o desenvolvimento moral, intelectual, cultural e físico dos associados e famílias.

\subsection{As misericórdias}

As misericórdias em Portugal são as instituições mais antigas e com maior vocação social do ponto de vista da sua tradição. Com efeito, data de 15 de agosto de 1498 a primeira misericórdia: a de Lisboa. A sua criação, iniciativa da Rainha D. Leonor, resultou da grande crise social e económica que grassava em Portugal por aquele tempo e dada a incapacidade das instituições, sobretudo ligadas à Igreja Católica (confrarias ou irmandades, albergarias, hospitais, gafarias ou leprosarias e mercearias) em fazer face a tantas necessidades. Neste contexto passou a caber às misericórdias a responsabilidade administrativa dos hospitais.

Manteve-se com ligeiras alterações quer o papel quer as atribuições das misericórdias no panorama da assistência social nacional, tendo hoje, após a criação da União das Misericórdias Portuguesas em 1976, uma vasta área de intervenção que vai da assistência na área da saúde à acção social nos seus mais variados aspectos.

\subsection{As Instituições Particulares de Solidarie- dade Social (IPSS)}

Não é fácil incluir o conjunto das associações no âmbito da economia social, principalmente em virtude da grande variedade e dispersão dos seus regulamentos e também porque os objectivos das associações se apresentam em muitos aspectos radicalmente diversos. No entanto, muitas das organizações que assentam a sua base nesta componente, constituem e integram plenamente o sector da economia social. Em Portugal, o vasto conjunto de associações de desenvolvimento social e local, são exemplo interessante no contexto das IPSS, ainda que não seja caso único. 
As IPSS em termos específicos são reguladas em Portugal pelo decreto-lei n. $^{\circ}$ 119/83, de 25 de Fevereiro, apresentando uma finalidade não lucrativa, constituindo-se por iniciativa de particulares com o propósito de dar expressão à solidariedade e justiça entre os indivíduos, no intuito da prestação de serviços que vão do apoio a crianças e jovens, à família, à integração sócia e comunitária, à protecção da saúde, educação e formação profissional dos cidadãos e à resolução de problemas habitacionais dos cidadãos.

Podem assumir a forma de associações de solidariedade social, de voluntários de acção social, de socorros mútuos, fundações de solidariedade social e irmandades de misericórdia.

\section{Considerações finais}

A economia social, em face do actual desenvolvimento da sociedade, apresenta-se com uma importância decisiva no que respeita ao seu papel na promoção da justiça social e da equidade. Na era da globalização e da concorrência como virtude principal dos mercados e tal como é aceite hoje em dia, os Estados são cada vez mais incapazes de acudir a todas as necessidades sociais que se apresentam aos indivíduos. E, dada também a clara incapacidade do mercado em promover os mesmos objectivos, surge a necessidade de uma terceira dimensão que, sem esquecer a liberdade individual que deve ser assegurada, permite, no entanto, criar ou ajudar a criar as necessárias estruturas para promoção do desenvolvimento económico e social da sociedade. À economia social, está por conseguinte atribuído um papel de charneira entre a chamada economia pública e a economia de mercado, no sentido da resolução dos problemas sociais e das necessidades sociais, que a primeira não consegue resolver, por estar fora da sua esfera de acção (excluídos sociais, incapacitados, etc.) ou por se tratar de bens públicos que pelas suas características não podem aproveitar de forma directa a todos. Quanto à economia de mercado não pretende, por manifesta falta de interesse, prover os bens de natureza social que se reivindicam para uma parcela de indivíduos que por motivos vários se encontram excluídos da sociedade, o que de qualquer modo a realizar-se impediria a resolução do seu principal objectivo: a maximização do lucro.

É por isto que a economia social tem vindo a adquirir um papel extraordinariamente importante na esfera marginal de actuação do mercado e do Estado. Ainda com mais evidência, pode afirmar-se que os últimos 30 anos têm vindo a demonstrar a importância da economia social na resposta às transformações sociais, económicas e politicas que se foram verificando na Europa e no mundo em geral e em Portugal de modo particular. O mundo globalizado, as crises económico-financeiras generalizadas em resultado daquele, os surtos de desemprego, as desigualdades sociais resultantes da incapacidade dos Estados na promoção da repartição equitativa dos rendimentos têm conduzido a economia social para um papel predominante nas respostas a muitas das questões que vão surgindo. Também a abertura das fronteiras na Europa e a liberalização dos mercados financeiros e de mercadorias trouxeram novas dificuldades e exigências, que obrigaram por seu lado, a novas modalidades de intervenção dos Estados no financiamento das actividades fundamentais para a coesão social e para a promoção da inclusão social e que, na maior parte das vezes, conduz a iniquidades e a uma clivagem maior entre pobres e ricos e à exclusão social.

Nestas circunstâncias, tem cabido à economia social criar através de mecanismos de solidariedade empresas e instituições que, para além de serem eficientes do ponto de vista económico, consagram, ao mesmo tempo, realizar aquilo que é o seu grande objectivo: promoção da inclusão social, o desenvolvimento social e a coesão social.

\section{Referências}

BAREA, J.; MONZÓN, J. L. (Dir.). Libro branco de la economia social en Espanha. Ministério de Trabajo y Seguridad Social, Madrid, 1992.

DEFOURNY, J. L. L'émergence du secteur d'economie sociale en Wallonie e en Europe. Boletín de Estudios y Documentación, Coperativismo y Economia Social. Ministerio de Trabajo y Seguridad Social, Madrid, 1991.

Origenes, contextos y funciones de un gran tercer sector. In: MONZÓN, J. L.; DEFOURNY, J. L. (Dir.). Economia social. Entre economia capitalista e economia pública. Madrid: CIRIEC, 1992. 
DEMOUSTIER, D. L'économie sociale et solidaire. S' associer pour entreprendre autrement, Paris, Syros, 2001.

CÓDIGO COOPERATIVO 1997. Disponível em: < $\underline{\text { http:// }}$ www.geocities.com/apn notarios/Codigos e Leis/ ccooperativo.htm>. Acesso em: jul. 2007.

FERREIRA, S. As organizações do terceiro sector na reforma da segurança social. In: CONGRESSO PORTUGUÊS DE SOCIOLOGIA 4, 17 a 19 de abr. 2000, Actas... Coimbra, 2000.

FRANCO, R. C. Controvérsia em torno de uma definição para o terceiro sector. A definição estrutural-operacional de John Hopkins versus a noção de economia social. In: CONGRESSOLUSO-AFRO-BRASILEIRODECIÊNCIAS SOCIAIS 8, 16 a 18 set. 2004, Actas ... Coimbra, 2004.

LIPIETZ, A. Pour le tiers secteur. L'économie sociale et solidaire: porquoi et comment, Paris: La Découvert, 2001.

NUNES, F.; RETO, L.; CARNEIRO, M. et al. O terceiro sector em Portugal: delimitação, caracterização e potencialidades. Lisboa: Instituto António Sérgio do Sector Cooperativo (Inscoop), 2001. Programa Pessoa-Linha de Acção, Estudos e Investigação.

MONZÓN, J. L. La economia social: tercer sector de un nuevo escenario. In: DEFOURNY, J. (Dir.).

Economia social. Entre economia capitalista e economia pública. Madrid: CIRIEC, 1992. p. 12.

OIT - ORGANIZAÇÃO INTERNACIONAL DO TRABALHO. Cooperativas. Disponível em: <http:// www.oitbrasil.org.br/prgatv/prg esp/cooper.php $>$. Acesso em: jul. 2007.

PEREIRINHA, J. Economia social e Estado-providência. Intervenção Social, Revista do Instituto Superior de Serviço Social de Lisboa e Beja, n. 27, jun. 2003.

PÉREZ, M. A. Pensamiento económico y economía social. Valência: Tirant lo Blanch, 1999.

RIBEIRO, E. A fragmentação do mercado de trabalho: os desafios levantados pelos novos desenvolvimentos. Intervenção Social, Revista do Instituto Superior de Serviço Social de Lisboa e Beja, n. 31, jun. 2005.

\section{Notas}

1 A questão coloca-se de imediato no sentido paradoxal em que os conceitos se posicionam. Com efeito, sendo a economia uma ciência eminentemente social por se traduzir numa actividade humana, é quase redundante falar em economia social, porquanto aquela já engloba esta, e terceiro sector, parece querer significar uma determinada hierarquização, de modo que falar em terceiro, implica considerar um segundo e um primeiro sector, que se encontrariam assim acima daquele, ou seja, o Estado e o mercado e só depois a componente social (PEREIRINHA, 2003).

2 Destes destacam-se os designados socialistas utópicos, como Robert Owen (1771-1858) e Charles Fourier (1772-1837), propondo a criação de um falanstério (espécie de comuna ideal). Ainda, Jean Phillippe Buchez (1796-1866), promotor das associações operárias de produção assim como as associações sindicais na industria; Fréderic Raiffaisen (1818-1888), promotor das cooperativas rurais com múltiplas funções. Contudo, seria com Constantin Pecqueur (18011887) e François Vidal (1812-1872) que se encontrariam referências explícitas à economia social. Ambos exaltam a associação ligada à intervenção doEstadoe desempenhariam umimportante papel na revolução de 1848. Um dos principais nomes da revolução foi o de Louis Blanc, escritor socialista que se havia de bater pela ideia das cooperativas de produção à frente do governo provisório.

3 Charles Guide foi professor de economia política e caracterizaria de forma determinante a perspectiva da economia social francesa. Ocupando uma posição original nas correntes cristãs sociais e na burguesia protestante, procura, acima de tudo, promover todos os esforços que conduzissem à emancipação da classe operária pelos seus próprios meios, recusando, no entanto, a luta de classes, por ser incompatível como o objetivo de penetração do evangelho na vida social. A sua contribuição, fundamental no âmbito da economia social, surge na procura da síntese entre o socialismo associativista e o cristianismo social.

4 Conforme, em termos de exemplo da confusão das utilizações dos vários termos, Franco (2004)e Ferreira (2000).

5 As perspectivas apresentadas são respectivamente do Padre Vítor Milícias, de Acácio Catarino eAlfredo Bruto da Costa, e mostram a discrepânciaquanto ao conceito de economia social e a sua significação(NUNES; RETO et al., 2001).

6 Para um aprofundamento desta temática, sugerimos Ribeiro (2005).

7 As sociedades anónimas laborais são um sector bastante recente mas já muito importante em Espanha, tendo-se evidenciado o seu desenvolvimento, sobretudo a partir da crise económica de 1973. Asua característica principalé a de que os trabalhadores detêm pelo menos $51 \%$ do capital, conferindo-lhes o seu funcionamento e estatuto traços distintivos face às restantes realidades de economia social ou privada, que lhes dão assim um enquadramento específico no plano da ecónomia social. 


\section{Joaquim Manuel Croca Caeiro}

Doutor em Ciências Sociais

Mestre em Ciência Política

Director do Instituto Superior de Serviço Social de Lisboa (ISSSL)

Docente das Unidades Curriculares de

Economia Social e Política Social

Instituto Superior de Serviço Social de Lisboa da Universidade Lusíada de Lisboa

Rua da Junqueira, 188-198

Lisboa - Portugal

1349-001 